OPEN ACCESS

Edited by:

Ying Xu,

University at Buffalo, USA

Reviewed by:

Michael Lardelli,

University of Adelaide, Australia Antonio Camins,

University of Barcelona, Spain

${ }^{*}$ Correspondence:

Hai-Rong Qian

qianhairong_cn@163.com

${ }^{\dagger}$ These authors have contributed equally to this work

Received: 19 December 2016 Accepted: 03 March 2017 Published: 21 March 2017

Citation:

Xia D-Y, Huang X, Bi C-F, Mao L-L,

Peng L-J and Qian H-R (2017) $P G C-1 \alpha$ or FNDC5 Is Involved in Modulating the Effects of $A \beta_{1-42}$ Oligomers on Suppressing the Expression of BDNF, a Beneficial Factor for Inhibiting Neuronal Apoptosis, A $\beta$ Deposition and Cognitive Decline of APP/PS1 Tg Mice. Front. Aging Neurosci. 9:65. doi: 10.3389/fnagi.2017.00065
PGC-1 $\alpha$ or FNDC5 Is Involved in Modulating the Effects of $A \beta_{1-42}$ Oligomers on Suppressing the Expression of BDNF, a Beneficial Factor for Inhibiting Neuronal Apoptosis, A $\beta$ Deposition and Cognitive Decline of APP/PS1 Tg Mice

\section{De-Yu Xia ${ }^{1+}$, Xin Huang ${ }^{2 \dagger}$, Chong-Feng $\mathrm{Bi}^{1}$, Lin-Ling Mao ${ }^{1}$, Li-Jun Peng ${ }^{1}$ and Hai-Rong Qian ${ }^{1 *}$}

${ }^{1}$ Department of Neurology, General Hospital of Navy, Beijing, China, ${ }^{2}$ Department of Neurology, Beijing Luhe Hospital, Capital Medical University, Beijing, China

Alzheimer's disease (AD) is generally defined as the aberrant production of $\beta$-amyloid protein $(A \beta)$ and hyperphosphorylated tau protein, which are deposited in $\beta$-amyloid plaques (APs) and neurofibrillary tangles (NFTs), respectively. Decreased levels of brain-derived neurotrophic factor (BDNF) have been detected in patients with $A D$ compared to control subjects. However, the underlying molecular mechanisms driving the downregulation of the BDNF remain unknown. Therefore, we explored the mechanisms underlying the regulation of BDNF in the neurons of APP/PS1 transgenic (Tg) mice, an AD experimental model. Using the APP/PS1 Tg mice, we found that BDNF expression was markedly downregualted the age of 3- and 9-month-old. After cerebroventricular injection (i.c.v) of $A \beta_{1-42}$ oligomers into the mice, BDNF was also found to be decreased, which demonstrated the critical roles of the $A \beta_{1-42}$ oligomers in regulating the expression of BDNF. In neuronal culture, peroxisome proliferators-activated receptor $\gamma$ coactivator $1 \alpha(P G C-1 \alpha)$ and fibronectin type III domain-containing 5 (FNDC5) were found to be downregulated by treatment with the $A \beta_{1-42}$ oligomers. In addition, overexpression of either PGC-1 $\alpha$ or FNDC5 reversed the suppressive effects of the $A \beta_{1-42}$ oligomers on the expression of BDNF in neuroblastoma $2 a$ (n2a) cells. More importantly, elevating the levels of PGC-1 $\alpha$, FNDC5 or BDNF in the n2a cells counteracted the effects of the $A \beta_{1-42}$ oligomers on neuronal apoptosis. Additionally, intranasal administration BDNF in the APP/PS1 Tg mice decreased the A $\beta$ deposition and reduced the cognitive decline of the mice.

Keywords: brain derived neurotrophic factor, PGC-1 $\alpha$, FNDC5, $\beta$-amyloid protein, Alzheimer's disease 


\section{INTRODUCTION}

Alzheimer's disease (AD) is characterized by the pathological production of $\beta$-amyloid protein $(A \beta)$ and hyperphosphorylation of tau in $\beta$-amyloid plaques (APs) or neurofibrillary tangles (NFTs) (Bloom, 2014). Since A $\beta$ accumulation multiple affects multiple biological functions, such as oxidative stress, neuroinflammation, neurotoxicity, autophagy and apoptosis (Yankner, 1996), the components of APs received a great amount of attention in prior works. For example, APs are essentially composed of $\mathrm{A} \beta_{1-42}$ (Glenner and Wong, 1984) and $\mathrm{A} \beta_{23-35}$ (Kubo et al., 2002; Gruden et al., 2007). As a consequence, different lengths of $A \beta$ fragments greatly impair the normal physiological functions of the brain.

Brain derived neurotrophic factor (BDNF) has been identified as a versatile and multifunctional growth factor implicated in the control of a wide spectrum of adaptive processes in both the developing and adult brain, which range from the modulation of synaptic connectivity and excitation in neurodegeneration (Park and Poo, 2013). In patients with $\mathrm{AD}$, the precursor form of BDNF and mature BDNF or its mRNA are decreased in the parietal cortex and hippocampus in the early stage of the disease (Phillips et al., 1991; Holsinger et al., 2000; Michalski and Fahnestock, 2003; Peng et al., 2005). In addition, serum levels of BDNF are also correlated with the severity of dementia (Laske et al., 2007). Interestingly, individuals with the Val66Met mutation in BDNF displays a decreased volume of specific brain regions and impaired learning ability (Egan et al., 2003). Blocking BDNF signaling with anti-TrkB antibodies induces cognitive decline in exercise animal models (Vaynman et al., 2006). For these reasons, BDNF has been suggested to control the aggregation of tau protein in NFTs (Murer et al., 1999). However, the roles of BDNF in $A \beta$ production and deposition remain to be determined, especially the underlying mechanisms.

Recently, peroxisome proliferator-activated receptor $\gamma$ coactivator $1 \alpha$ (PGC-1 $\alpha)$ and fibronectin type III domain containing 5 (FNDC5) were previously shown to be responsible for regulating the expression of BDNF in mice (Wrann et al., 2013). PGC-1 $\alpha$ was initially identified as a beneficial factor that was induced in skeletal muscle by exercise (Finck and Kelly, 2006). A subsequent study revealed the important role of PGC- $1 \alpha$ in the inhibition of the neurodegeneration (Ma et al., 2010). PGC-1 $\alpha$ has been suggested to exert neuroprotective effects against MPTP-induced Parkinson's disease (St-Pierre et al., 2006). In addition, PGC- $1 \alpha$ also negatively regulates $\mathrm{N}$-methyl-D-aspartate (NMDA) receptor activities, which results in reduction of excessive excitotoxicity in rat cortical neurons (Cheng et al., 2012). FNDC5 was identified as a PGC- $1 \alpha-$ dependent myokine (Bostrom et al., 2012), that is expressed in the brain (Dun et al., 2013). In addition, a previous study showed that FNDC5 is located downstream of PGC- $1 \alpha$ to modulate BDNF regulation in mice (Wrann et al., 2013).

Although these investigations have provided fragments of information about the potential connections between FNDC5/PGC- $1 \alpha$ and BDNF, their potential contributions to $\mathrm{AD}$ still remain unknown. Therefore, we aimed to reveal the mechanisms of BDNF downregulation during the course of $\mathrm{AD}$ development and progression. In addition, the effects of BDNF on neuronal apoptosis, $\mathrm{A} \beta$ deposition and learning ability were further addressed.

\section{MATERIALS AND METHODS}

\section{Reagents}

$\mathrm{A} \beta_{1-42}$ was synthesized by Qiangyao Biotechnology (Shanghai, China). BDNF was obtained from Sigma-Aldrich Corp (St. Louis, MO, USA). Antibodies specific for BDNF, PGC- $1 \alpha$, and FNDC5 were obtained from Abcam (Shanghai, China). Antibodies against A $\beta$ (Stock \#2454) and $\beta$-actin were purchased from Cell Signaling Technology, Inc. (Danvers, MA, USA). Of note, the $A \beta$ antibody specifically reacts with human $A \beta$. PGC$1 \alpha$ or FNDC5 cDNA plasmids were obtained from Origene Technologies (Rockville, MD, USA) and subcloned into the pCMV6-XL vector. All reagents for the qRT-PCR and SDSPAGE experiments were purchased from Bio-Rad Laboratories. All other reagents are from Invitrogen (Carlsbad, CA, USA) unless otherwise specified.

\section{Cell Culture}

Mouse neuro-2a (n2a) cells were grown $\left(37^{\circ} \mathrm{C}\right.$ and $\left.5 \% \mathrm{CO}_{2}\right)$ on $6-\mathrm{cm}$ tissue culture dishes $\left(10^{6}\right.$ cells per dish) in DMEM supplemented with $10 \%$ FBS medium. To enhance the efficacy of transfection (Son et al., 2000), the cells were transfected with cDNA constructs of PGC- $1 \alpha$ and FNDC5 in serum-free medium using lipofectamine 2,000, and the cells were maintained in serum-free medium for an additional $12 \mathrm{~h}$ before incubation with the $\mathrm{A} \beta_{1-42}$ oligomers.

\section{Transgenic Mice and Treatments}

The wild-type (WT) and APP/PS1 [B6C3-Tg (APPswe, PSEN1dE9) 85Dbo/J (Stock Number: 004462)] Tg mice were obtained from The Jackson laboratory (Bar Harbor, ME, USA). Genotyping was performed at 3-4 weeks after birth. The mice were housed in a controlled environment under a standard room temperature, relative humidity and 12-h light/dark cycle with free access to food and water. The general health and body weight of the animals were monitored every day. The mouse brains from the different groups were collected under anesthesia and perfusion.

\section{$A \beta_{1-42}$ Oligomers Preparation}

The methods for preparing $A \beta_{1-42}$ oligomers has been described previously (Pan et al., 2011). In brief, freeze-drying $A \beta_{1-42}$ protein was initially monomerized by dissolution it to a final concentration of $1 \mu \mathrm{g} / \mu \mathrm{l}$ in $100 \%$ hexafluoroisopropanal (HFIP) and the solution was aliquoted in sterile eppendorf tubes. HFIP was then evaporated under vacuum and the peptide was stored at $-20^{\circ} \mathrm{C}$ before reconstituent. For preparing $\mathrm{A} \beta_{1-42}$ oligomers, the peptide was initially resuspended in dimethylsulfoxide (DMSO) to $20 \mu \mathrm{g} / \mu \mathrm{l}$ with water bath ultrasonication for $10 \mathrm{~min}$ and the solution was then diluted to a final concentration of $0.2 \mu \mathrm{g} / \mu \mathrm{l}$ in phenol red-free F-12 media, and incubated at $4^{\circ} \mathrm{C}$ for $24 \mathrm{~h}$. 


\section{Real-Time PCR}

Real-Time PCR assays were performed with the MiniOpticon Real-Time PCR detection system (Bio-Rad) using total RNA and the GoTaq 1-step Real-Time PCR kit with SYBR Green (Promega) and the appropriate primers. The reaction mixtures were incubated at $50^{\circ} \mathrm{C}$ for $15 \mathrm{~min}$ and then $97^{\circ} \mathrm{C}$ for 5 min. Then, 35 PCR cycles were performed with the following temperature profiles: $97^{\circ} \mathrm{C}$ for $15 \mathrm{~s}, 58^{\circ} \mathrm{C}$ for $30 \mathrm{~s}, 68^{\circ} \mathrm{C}$ for $1 \mathrm{~min}$, and $77^{\circ} \mathrm{C}$ for $1 \mathrm{~min}$. Data were collected at the final step $\left(77^{\circ} \mathrm{C}\right.$ for $1 \mathrm{~min}$ ) to prevent the inclusion of any fluorescence from primer dimers. The GenBank accession number and forward and reverse primers are as follows: mouse BDNF (NM_007540) F-TGA GCAAAGCCGAACTTCTC, R-TCACCTGGTGGAACATTGT G; PGC-1 $\alpha$ (NM_008904) F-TGATGTGAATGACTTGGATAC AGACA, R-GCTCATTGTTGTACTGGTTGGATATG; FNDC5 (NM_027402) F-ATGAAGGAGATGGGGAGGAA, R-GCGGC AGAAGAGAGCTATAACA, and GAPDH (NM_001289726) FACTCCACTCACGGCAAATTC, R-GGAGATGATGACCCTT TTGG. The gene expression values were normalized to those of GAPDH. Of note, the control group was always set as 1 and the experimental groups were compared to the control groups as previously described (Roberts et al., 2011).

\section{Western Blots}

The tissues or cells were lysed in radio-immune precipitation assay buffer (25 mM Tris-HCl [pH 7.6], $150 \mathrm{mM} \mathrm{NaCl}, 1 \%$ NP-40, $1 \%$ sodium deoxycholate, and $0.1 \%$ SDS) containing a protease inhibitor cocktail (Pierce Chemical Company, Shanghai, China). The protein content of the cell lysates was determined using a bicinchoninic acid (BCA) protein assay reagent (Pierce Chemical Company, Shanghai, China). The total cell lysates $(4 \mu \mathrm{g})$ were subjected to SDS-PAGE, transferred to a membrane, and probed with a panel of specific antibodies. Each membrane was only probed with one antibody. $\beta$-actin was used as a loading control. All western blots were performed at least in triplicate using a different cell preparation each time.

\section{Intracerebroventricular Injection}

$A \beta$ or vehicle (PBS) were intracerebroventricularly injected (i.c.v) into C57BL/6 mice. Briefly, stereotaxic injections were conducted at the following coordinates from the bregma: mediolateral: -1.0 $\mathrm{mm}$; anteroposterior: $-0.22 \mathrm{~mm}$; and dorsoventral: $-2.8 \mathrm{~mm}$. Following the injections, each mouse recovered spontaneously on a heated pad. The reliability of the injection sites was validated by injecting trypan blue dye (Invitrogen) into separate cohorts of mice and observing staining in the cerebral ventricles. $24 \mathrm{~h}$ after the injection, the mouse brains were harvested after anesthesia and perfusion.

\section{Immunohistochemistry}

Mouse brains were collected from the WT or APP/PS1 Tg mice and fixed with $4 \%$ paraformaldehyde. Serial sections $(10 \mu \mathrm{M}$ thick) were cut using a cryostat (Leica, CM1850, Germany). The slides were first rehydrated in a graded series of ethanol and submerged in $3 \%$ hydrogen peroxide to eliminate endogenous peroxidase activity. The levels of BDNF and $\mathrm{A} \beta$ were determined using an immunohistochemical staining kit with antibodies specific for $\mathrm{BDNF}$ (1:200 dilution in $\mathrm{PB}$ solution) and $\mathrm{A} \beta$ (1:200 dilution in $\mathrm{PB}$ solution), following the manufacturer's instructions (Invitrogen).

\section{Viability Assay}

Neuronal viability was determined by an MTT assay with minor modifications. In brief, $\mathrm{n} 2 \mathrm{a}$ cells were incubated with an $\mathrm{Ab}$ in the absence or presence of BDNF. After the treatments, Tiler $96^{\circledR}$ Aqueous One Solution $(20 \mu \mathrm{l})$ was added to the corresponding wells and the cells were further incubated for $4 \mathrm{~h}$. The optical density was measured by a microplate reader (Bio-Rad, Bio-Rad Laboratories, Inc., Hercules, California, USA) at a wavelength of $490 \mathrm{~nm}$.

\section{Flow Cytometry}

Annexin V-FITC/PI double staining was used to detect the apoptosis of n2a and SH-SY5Y cells. In detail, the cells were collected with an enzyme-free cell dissociation buffer and washed twice with cold PBS (-) before centrifugation at 2,500 rpm for 5 min (Thermo Fisher Scientific Inc., Waltham, MA, USA). The cell pellets were then resuspended in $500 \mu$ l binding solution with $5 \mu \mathrm{l}$ annexin-V-fluorescein isothiocyanate and $5 \mu \mathrm{l}$ of propidium iodide before the analysis with a FACS Calibur flow cytometer (Becton, Dickinson and Company, Franklin Lakes, New Jersey, USA).

\section{Morris Water Maze}

The mice were trained and tested in a Morris water maze. In brief, the mice were pretrained in a circular water maze with a visible platform for 2 days. The platform was then submerged inside the maze, with the deck $0.5 \mathrm{~cm}$ below the surface of the water for the following experiments. Milk was added to the water to hide the platform from sight. The mice were placed inside the maze to swim freely until they found the hidden platform. The whole experiment took place over 7 days. For the first 6 days, the mice were placed in the maze with a maximum of $60 \mathrm{~s}$ to find the platform. The learning sessions were repeated with 4 trials each day, and an interval of $1 \mathrm{~h}$ between each session. The spatial learning scores (the latency period necessary to find and climb onto the hidden platform and the length of the path to the platform) were recorded. On the last day, the platform was removed, and the times that the mice passed through the memorized region were recorded for a period of $2 \mathrm{~min}$ (120 s). Finally, the recorded data were analyzed with a statistical program (ZH0065; Zhenghua Bioequipment, Yuanyang City, Henan, China).

\section{Animal Committee}

All animals were handled according to the guidelines of the Care and Use of Medical Laboratory Animals (Ministry of Health, Peoples Republic of China, 1994), and all experimental protocols were approved by the Laboratory Ethics Committees of the Navy General Hospital, China.

\section{Statistical Analysis}

All data are presented as the means \pm S.E. of at least three independent experiments. The statistical significance of the 
differences between the means was determined with Student's $t$-test or one-way ANOVA, as appropriate.

\section{RESULTS}

\section{BDNF Is Downregulated in APP/PS1 Tg Mice, and $A \beta_{1-42}$ Oligomers Can Decrease the Expression of BDNF in the C57BL/6 Mice}

Since previous studies have shown that BDNF is associated with neuroprotective effects (Kitiyanant et al., 2012; Wang et al., 2015), we first determined the expression levels of BDNF in
APP/PS1 Tg mice at 3 months of age. As shown in Figure 1A, BDNF immunostaining was evident in the cerebral cortex and hippocampus of 3-month-old C57BL/6 mice, and the positive staining was reduced in 3-month-old APP/PS1 Tg mice. To further confirm this finding, we examined the mRNA and protein levels of BDNF in the APP/PS1 Tg mice. In agreement with the immunostaining data, the mRNA and protein levels of BDNF were downregulated in both the cerebral cortex and hippocampus of the mice (Figure 1B and Supplemental Figure 1A). To reveal a possible reason for the downregulation of BDNF, we injected $A \beta_{1-42}$ oligomers (i.c.v) into 3-monthold C57BL/6 mice. The results demonstrated that the $\mathrm{A} \beta_{1-42}$ oligomer injection (i.c.v) significantly suppressed the expression
A

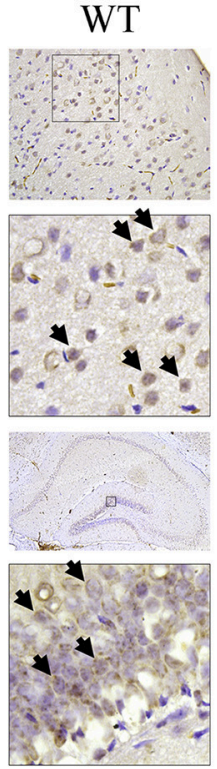

B

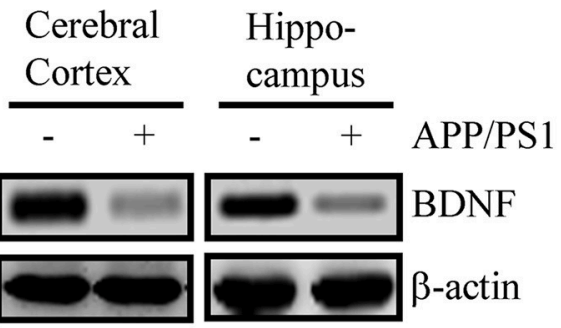

APP/PS1
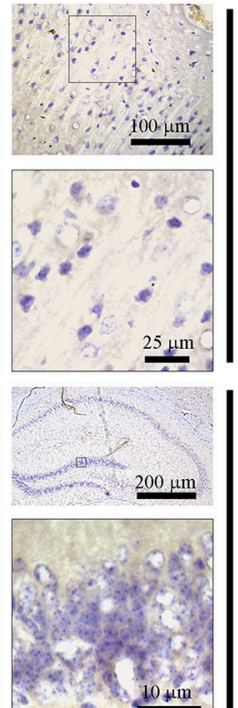

Hippocampus

Cortex

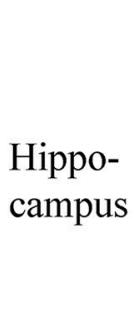

C
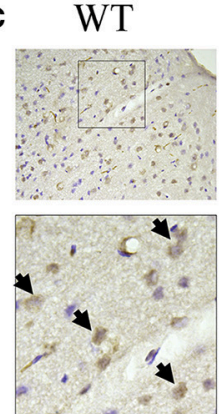
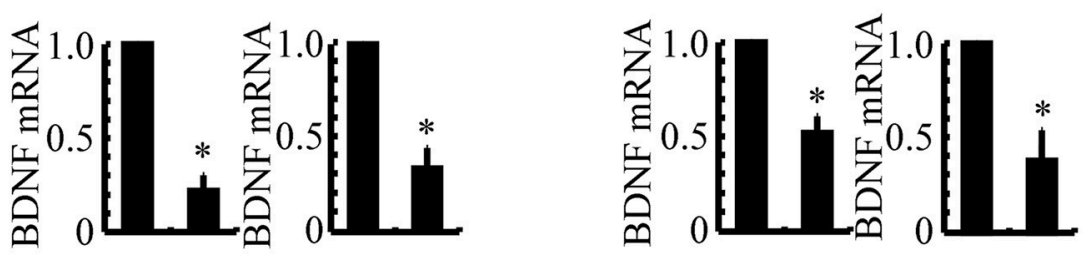

$\mathrm{A} \beta$

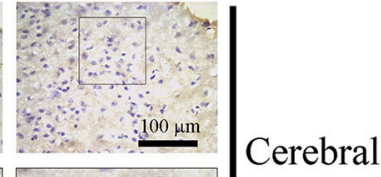

Cortex

Hippo-

campus

FIGURE 1 | The expression of BDNF was downregulated in APP/PS1 Tg mice and A $\beta_{1-42}$ oligomer injection decreased the expression of BDNF in C57BL/6 mice. (A,B) The brains of the 3-month-old APP/PS1 Tg mice were collected after anesthesia and perfusion ( $n=8)$. (C,D) In select experiments, the $\mathrm{A} \beta_{1-42}$ oligomers (1 $\mathrm{ng} / 5 \mu \mathrm{l}$ ) or vehicle (PBS) was injected (i.c.v) into the ventricles of the 3-month-old C57BL/6 mice ( $\left.n=8\right)$. (A,C) The immunoreactivity of BDNF was determined by $\mathrm{HHC}$ with a BDNF-specific antibody before the analysis with microscopy. (B,D) The mRNA and protein levels of BDNF were determined by qRT-PCR and western blots, respectively. GAPDH and $\beta$-actin served as the internal controls. The data represent the means $\pm \mathrm{S}$. E. of all the experiments. ${ }^{\star} p<0.05$ compared with WT or vehicle-treated controls. 
of BDNF in 3-month-old C57BL/6 mice (Figure 1C). Similar to these immunostaining results, the western blot and realtime PCR results also revealed the inhibitory effects of the $\mathrm{A} \beta_{1-42}$ oligomers on the expression of BDNF (Figure $1 \mathrm{D}$ and Supplemental Figure 1B). Consistent with these observations, our data revealed that BDNF expression is downregulated in APP/PS1 Tg mice, and BDNF expression is markedly decreased in $\mathrm{C} 57 \mathrm{BL} / 6 \mathrm{~J}$ mice injected with exogenous $A \beta_{1-42}$ oligomers, which supports a critical roles of $A \beta_{1-42}$ oligomers in suppressing the expression of BDNF during the course of $\mathrm{AD}$ development and progression.

\section{$A \beta_{1-42}$ Oligomers Decreased the Expression of BDNF through a PGC- $1 \alpha-$ or FNDC5-Dependent Mechanisms}

We next sought to elucidate the mechanisms of BDNF regulation in the APP/PS1 Tg mice. Since a previous study suggested that PGC- $1 \alpha$ or FNDC5 are responsible for BDNF regulation (Wrann et al., 2013), we first evaluated the effects of $A \beta$ oligomers on the expression of PGC- $1 \alpha$ and FNDC5. To this end, n2a cells were treated with $A \beta$ oligomers for $24 \mathrm{~h}$. Treatment of the $n 2 \mathrm{a}$ cells with $\mathrm{A} \beta$ oligomers decreased the expression of PGC- $1 \alpha$ and FNDC5 in the n2a cells (Figures 2A,B and Supplemental Figure 1C). To further elucidate the potential roles of PGC$1 \alpha$ and FNDC5 in regulating the expression of BDNF, we transfected the n2a cells with cDNA constructs of PGC- $1 \alpha$ and FNDC5. The efficacy of transfection was confirmed by western blots and real-time PCR. The results demonstrated that PGC- $1 \alpha$ and FNDC5 cDNA transfection significantly increased the mRNA and protein expression of corresponding genes (Figures 2C,D and Supplemental Figure 1D). Overexpression of the PGC- $1 \alpha$ and FNDC5 markedly reversed the inhibitory effects of $A \beta_{1-42}$ oligomers on the mRNA and protein expression of BDNF in the n2a cells (Figure 2E and Supplemental Figure 1E). Based on these findings, our findings demonstrated that $A \beta_{1-42}$ suppressed the expression of BDNF through a PGC- $1 \alpha$ - and FNDC5-dependent mechanism.

\section{Elevating the Levels of PGC-1 $\alpha$, FNDC5 and BDNF Alleviates the Apoptotic Effects of $A \beta_{1-42}$ Oligomers on Neurons}

Since the $A \beta_{1-42}$ oligomers are critical for suppressing the expression of BDNF in a PGC-1 $\alpha$ - and FNDC5-dependent manner, we were prompted to elucidate the biological roles of $\mathrm{BDNF}$ in neurons. Therefore, the $\mathrm{n} 2 \mathrm{a}$ cells were transfected with cDNA constructs of PGC- $1 \alpha$ and FNDC5 before the treatment with the $A \beta_{1-42}$ oligomers. Using an MTT assay, we found that the $A \beta$ oligomers clearly suppressed neuronal viability (Figure 3A). More interestingly, the PGC- $1 \alpha$ and FNDC5 overexpression significantly reduced the negative effects of the $A \beta_{1-42}$ oligomers on neuronal viability (Figure 3A). To determine the mechanism of the observed neuronal death, the $\mathrm{n} 2 \mathrm{a}$ cells were double stained with PI and annexin V after the indicated treatment. With flow cytometry, we found that the $\mathrm{A} \beta_{1-42}$ oligomers clearly induced neuronal apoptosis, which was

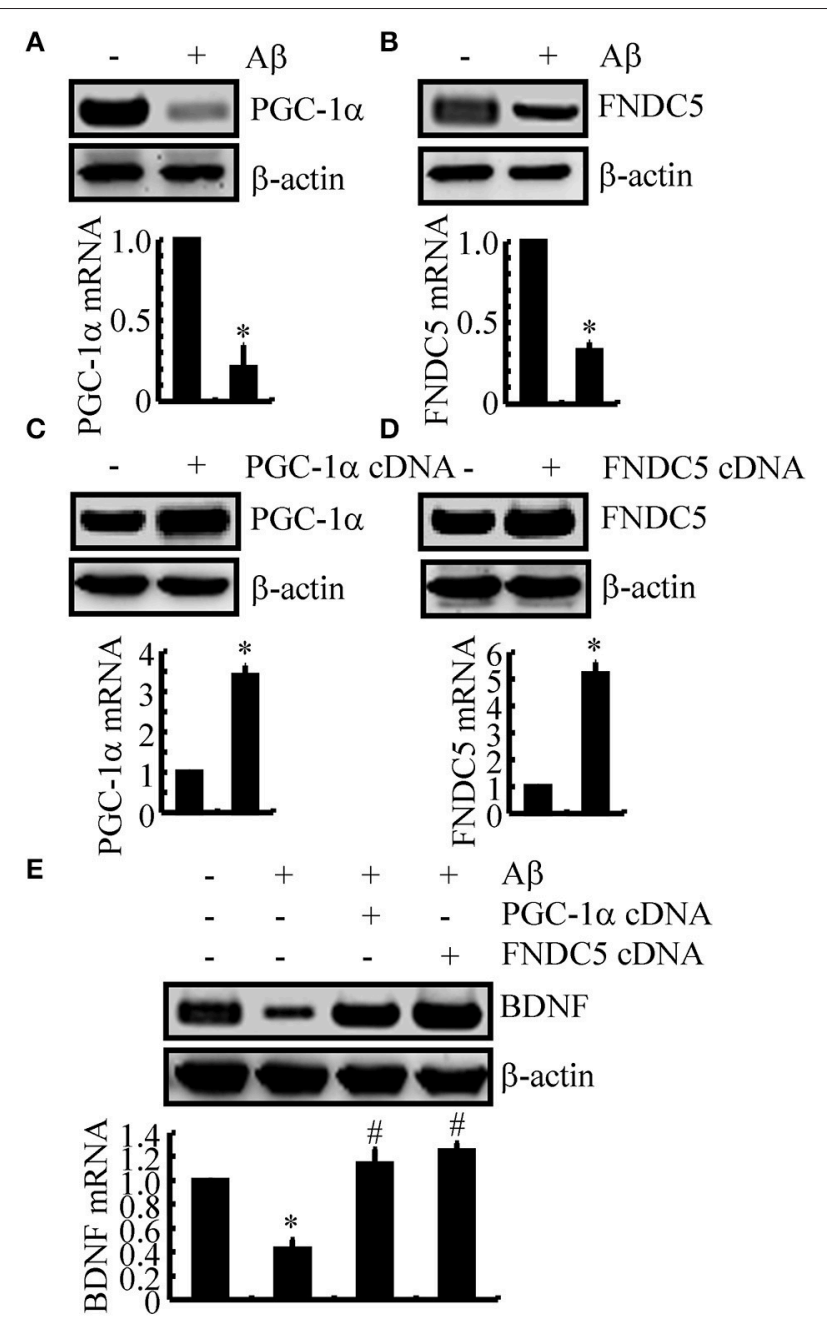

FIGURE 2 | The $A \beta_{1-42}$ oligomers suppressed the expression of BDNF through a PGC-1 $\alpha$ - and FNDC5-dependent mechanism. (A,B) The $n 2 a$ cells were treated with $A \beta$ oligomers $(1 \mathrm{ng} / \mathrm{ml})$ for $48 \mathrm{~h}$. (C,D) In select experiments, the $\mathrm{n} 2 \mathrm{a}$ cells were transfected with either PGC- $1 \alpha$ or FNDC5 cDNA for $48 \mathrm{~h}$. (E) In separate experiments, the n2a cells were transfected with either PGC- $1 \alpha$ or FNDC5 cDNA before the treatment with A $\beta$ oligomers for $48 \mathrm{~h}$. The mRNA and protein levels of BDNF, PGC- $1 \alpha$ and FNDC5 were determined by qRT-PCR and western blots, respectively. GAPDH and $\beta$-actin served as the internal controls. The data represent the means \pm S.E. of three times experiments. ${ }^{*} p<0.05$ compared with vehicle-treated or vector-transfected controls. $\# p<0.05$ compared with $A \beta$-treated alone.

reversed by the transfection with the PGC- $1 \alpha$ and FNDC5 cDNA constructs (Figure 3B).

Due to the ability of PGC- $1 \alpha$ and FNDC5 to modulate the expression of BDNF, we further determined the roles of $\mathrm{BDNF}$ in neuronal survival. To this end, we treated the $\mathrm{n} 2 \mathrm{a}$ cells with the $A \beta_{1-42}$ oligomers in the absence or presence of BDNF for the indicated times. The results demonstrated that BDNF treatment partially reversed the effects of the $\mathrm{A} \beta_{1-42}$ oligomers on neuronal death (Figure 3C). Similarly, BDNF also attenuated the apoptosis of the $A \beta_{1-42}$ oligomerstimulated n2a cells (Figure 3D). These observations clearly demonstrated that elevating the levels of PGC- $1 \alpha$, FNDC5 
A

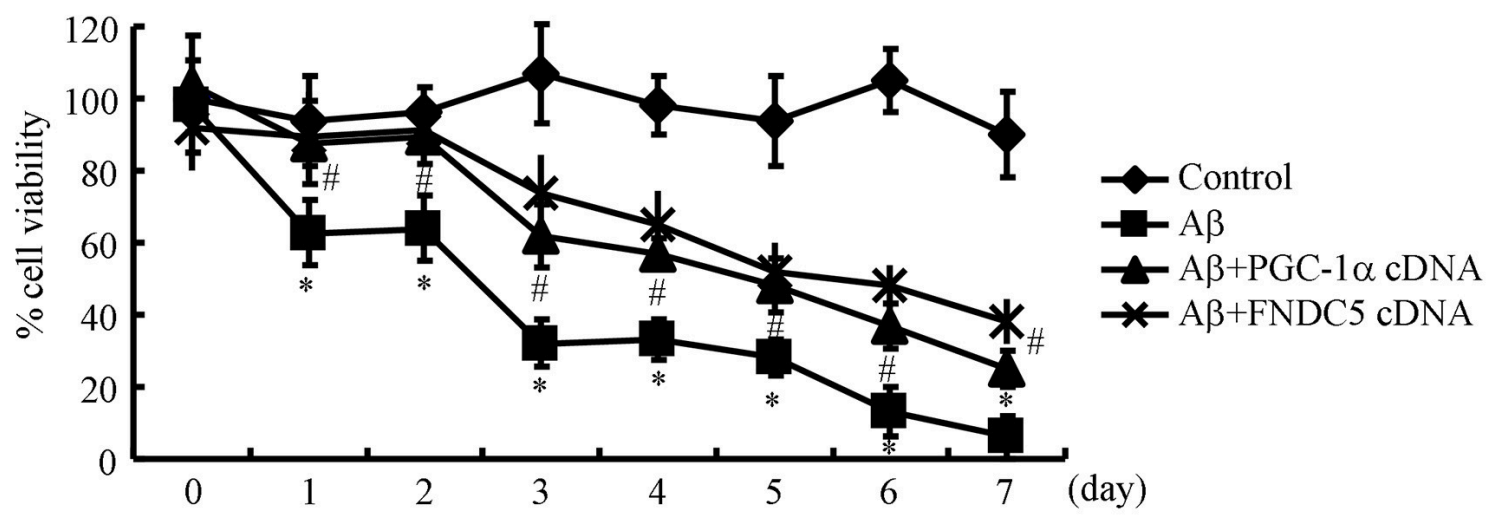

B

\section{Control}

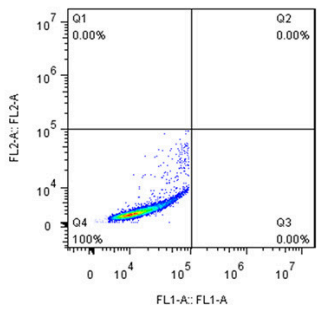

$\mathrm{A} \beta$

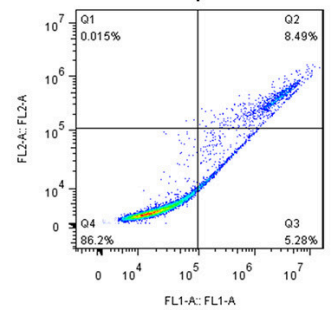

$\mathrm{A} \beta+\mathrm{PGC}-1 \alpha \mathrm{cDNA}$

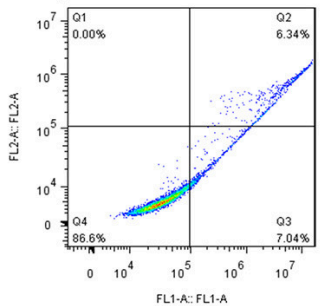

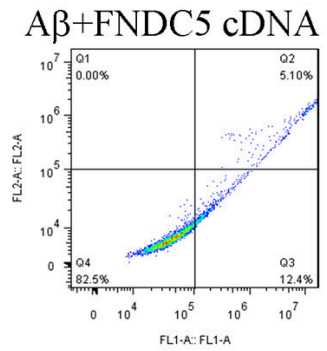

C

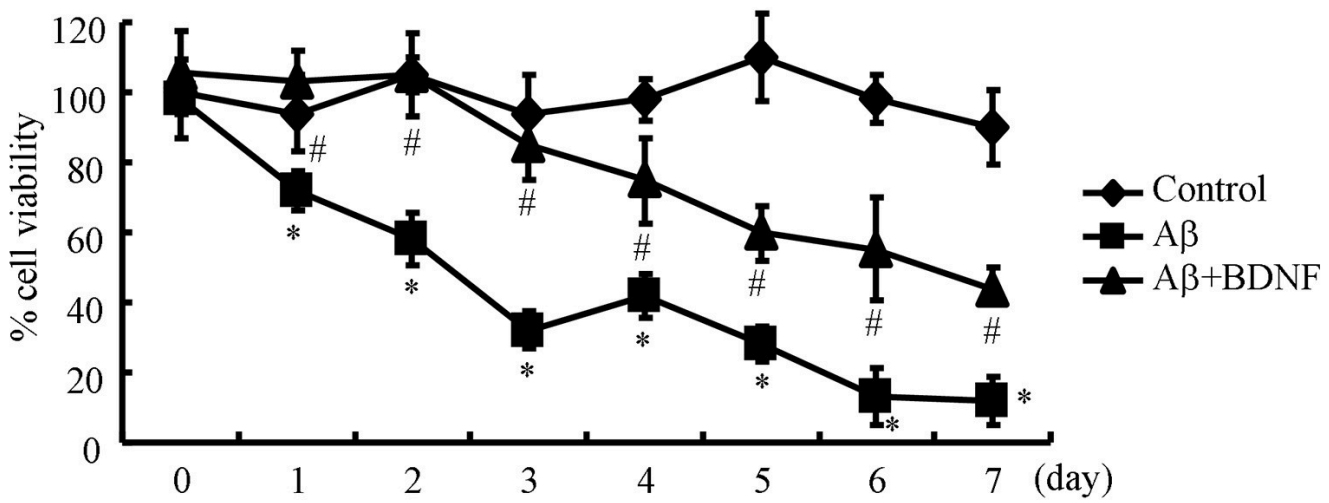

D
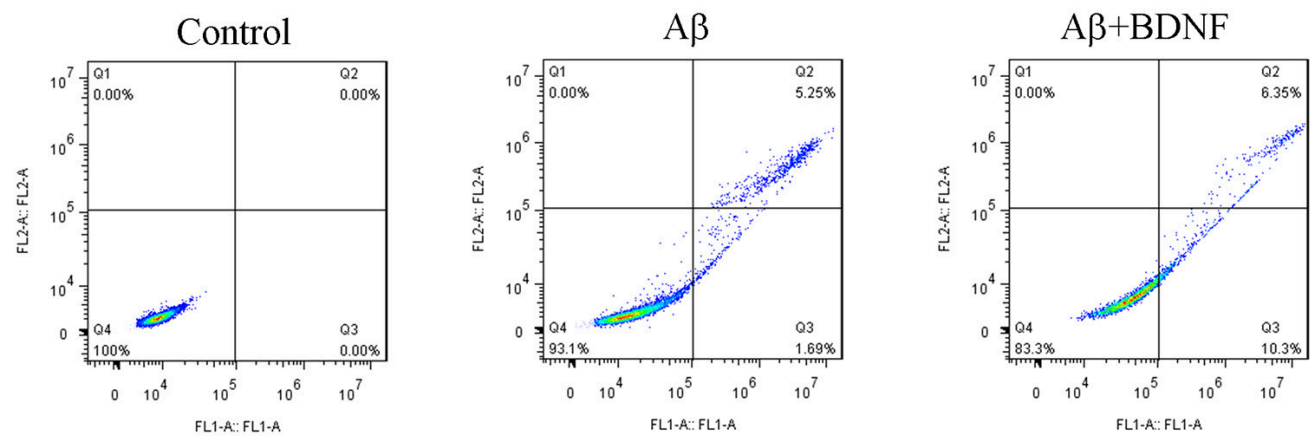

FIGURE 3 | Elevating the levels of PGC-1 $\alpha$, FNDC5 and BDNF partially protected neurons from $A_{1-42}$ oligomer-induced apoptosis. (A,B) The neurons were incubated with $A \beta(1 \mathrm{ng} / \mathrm{ml})$ in the absence or presence of transfection with either PGC-1 $\alpha$ or FNDC5 CDNA. (C,D) In select experiments, the $\mathrm{n} 2 \mathrm{a}$ cells were incubated with $A \beta(1 \mathrm{ng} / \mathrm{ml})$ in the absence or presence of BDNF $(1 \mathrm{ng} / \mathrm{ml})$. (A,C) The viability of neurons in different groups was determined by an MTT assay. (B,D) The apoptosis of neurons was determined by flow cytometry after staining with Pl and annexin $\mathrm{V}$. The data represent the means $\pm \mathrm{S}$. E. of three times experiments. ${ }^{*} p$ $<0.05$ compared with vehicle-treated or vector-transfected controls. ${ }^{\#} p<0.05$ compared with A $\beta$-treated alone. 
and $\mathrm{BDNF}$ ameliorates the effects of the $\mathrm{A} \beta_{1-42}$ oligomers on neuronal apoptosis.

\section{BDNF Treatment Suppresses the Deposition of $A \beta$ and Reduces the Cognitive Decline of the APP/PS1 Tg Mice}

Since BDNF counteracted the effects of the $A \beta_{1-42}$ oligomers on neuronal apoptosis, we next sought to determine the roles of
BDNF in the aggregation of $A \beta$ and the cognitive decline of the APP/PS1 Tg mice. The results demonstrated that the deposition and aggregation of $\mathrm{A} \beta$ was highly induced in the APP/PS1 Tg mice and $A \beta$ was deposited in the APs in the 9-month-old $\mathrm{APP} / \mathrm{PS} 1 \mathrm{Tg}$ mice (Figure 4A). As BDNF is downregulated in 9month-old APP/PS1 Tg mice (Supplemental Figure 2), we added back $\mathrm{BDNF}$ to the mice in order to determine the roles of BDNF in the deposition of $\mathrm{A} \beta$. Of note, the BDNF treatment partially decreases the number of APs in the 9-month-old APP/PS1 Tg
A
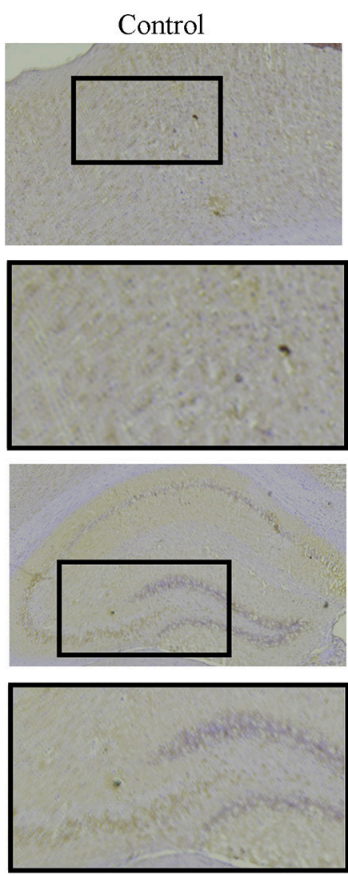

B
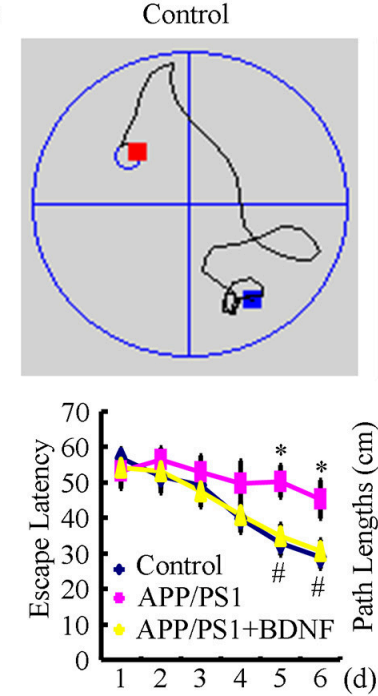
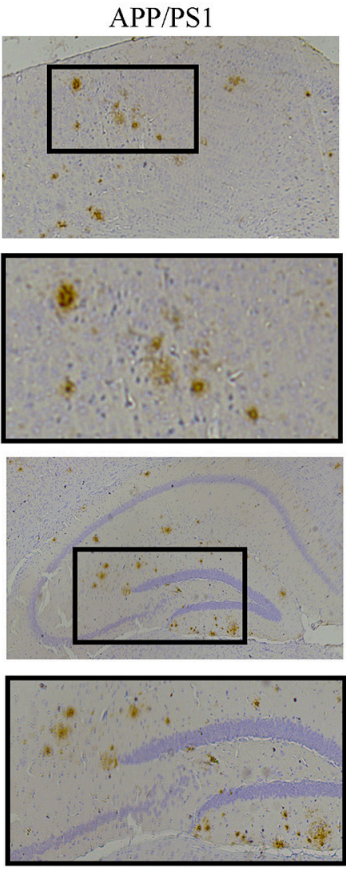

APP/PS1
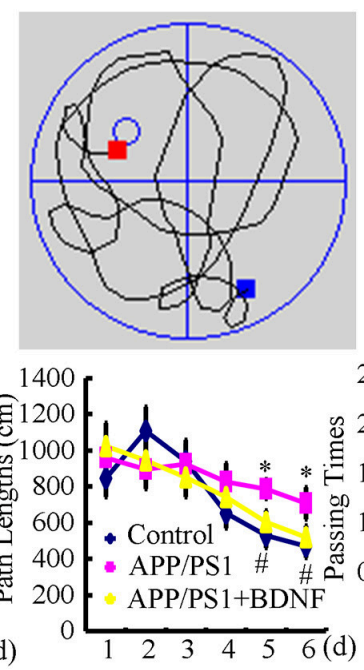

APP/PS1+BDNF
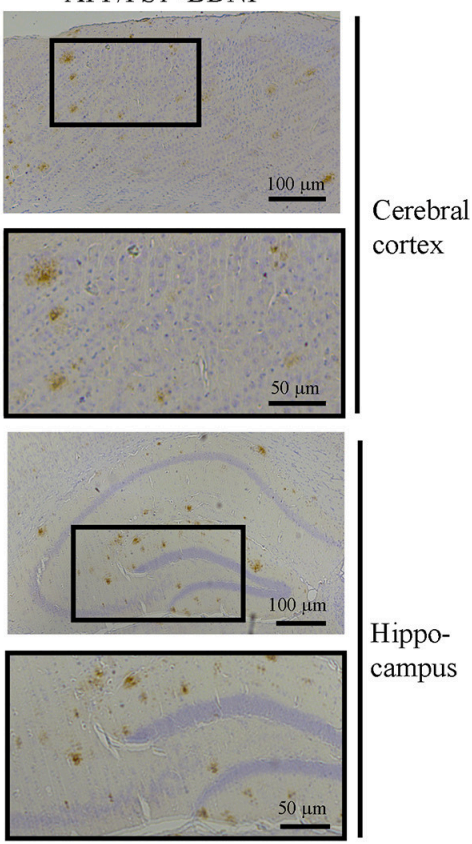

APP/PS1+BDNF
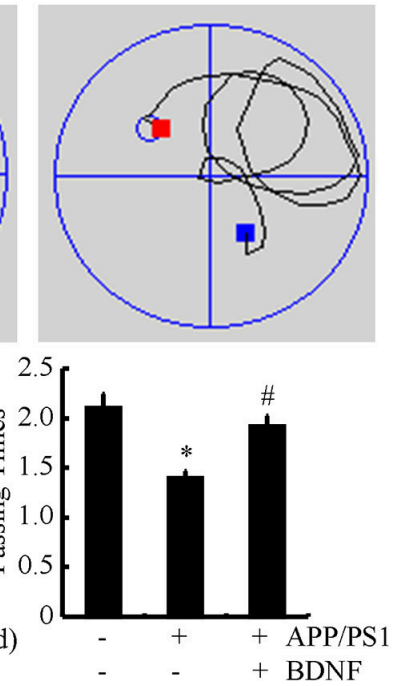

FIGURE 4 | BDNF treatment inhibits the deposition of $\mathbf{A} \beta$ and alleviates the cognitive decline of the APP/PS1 Tg mice. The APP/PS1 Tg mice at 3 months of age received BDNF $(1 \mathrm{ng} / 5 \mu \mathrm{l} / \mathrm{d})$ intranasally for 6 months $(n=7)$. (A) The number of APs was determined by IHC using an A $\beta$-specific antibody. (B) The learning ability of the different groups of mice was determined by the Morris maze test. ${ }^{*} p<0.05$ compared with vehicle-treated controls. ${ }^{\#} p<0.05$ compared with A $\beta$-treated alone. 
mice (Figure 4A). These observations demonstrate BDNF is beneficial for decreasing the deposition of $\mathrm{A} \beta$ in the APP/PS1 Tg mice.

Since we observed that the BDNF decreases the number of APs, we next investigated the relationship between brain BDNF levels and memory deficits in the APP/PS1 Tg mice. To this end, we assessed both spatial learning and memory abilities with the Morris water maze task. The results demonstrated that the untreated APP/PS1 Tg mice exhibited unequivocal learning deficits in the Morris water maze at 9 months of age (Figure 4B). The BDNF treatment improved the cognitive decline of the APP/PS1 Tg mice (Figure 4B). When we performed a probe test at $24 \mathrm{~h}$ after the last training trial, the untreated APP/PS1 Tg mice showed no preference for the target quadrant, which indicated significant memory impairment, whereas the BDNFtreated APP/PS1 Tg mice performed better than the non-treated APP/PS1 Tg mice (Figure 4B). These results clearly revealed that BDNF expression was downregulated in the APP/PS1 Tg mice and that the $\mathrm{A} \beta_{1-42}$ oligomers played critical roles in decreasing the expression of BDNF through a PGC-1 $\alpha$ - and FNDC5dependent mechanism. Reciprocally, elevating the levels of PGC$1 \alpha$, FNDC5 and BDNF partially ameliorated the negative effects of the $A \beta_{1-42}$ oligomers on neuronal survival. Additionally, the BDNF treatment clearly decreased the deposition of $\mathrm{A} \beta$ and reduced the cognitive decline of the APP/PS1 Tg mice.

\section{DISCUSSION}

$\mathrm{AD}$ is characterized by the aberrant production of $\mathrm{A} \beta$ and hyperphosphorylated tau, which aggregate in APs and NFTs, respectively (Bloom, 2014). Recently, BDNF expression was found to be downregulated in conjunction with the development and progression of AD (Phillips et al., 1991; Holsinger et al., 2000; Michalski and Fahnestock, 2003; Peng et al., 2005). However, the underlying mechanisms of the relationship between BDNF and $\mathrm{AD}$ remained unknown. Therefore, we sought to determine the mechanisms of BDNF downregulation, and the beneficial effects of $\mathrm{BDNF}$ on $\mathrm{AD}$. Indeed, the $A \beta_{1-42}$ oligomers have the ability to inhibit the expression of BDNF through a PGC-1 $\alpha$ and FNDC5-dependent mechanism. Reciprocally, treatment of neurons with exogenous BDNF prevents the $A \beta_{1-42}$ oligomersinduced neuronal apoptosis. Additionally, the BDNF treatment has the ability to alleviate the aggregation of $A \beta$ and reduce the cognitive decline of the APP/PS1 Tg mice (Figure 5).

$\mathrm{BDNF}$ expression is tightly regulated in physiological conditions. In $\mathrm{AD}$ patients, $\mathrm{BDNF}$ expression was shown to be downregulated in conjunction with the development and progression of AD (Phillips et al., 1991; Holsinger et al., 2000; Michalski and Fahnestock, 2003; Peng et al., 2005). In agreement with these prior works, we found that the expression of BDNF was downregulated in the APP/PS1 Tg mice. More interestingly, we further identified the $A \beta_{1-42}$ oligomers as the key factors that inhibit the expression of BDNF in the APP/PS1 Tg mice. Consistent with our observations, Lattanzio et al. (2016) reported that $A \beta_{25-35}$ has ability to suppress the expression of BDNF in $\mathrm{SH}-\mathrm{SY} 5 \mathrm{Y}$ cells. Furthermore, A $\beta$ oligomers are able to reduce the expression of BDNF in the APOE4 Tg mice (Sen et al., 2015).

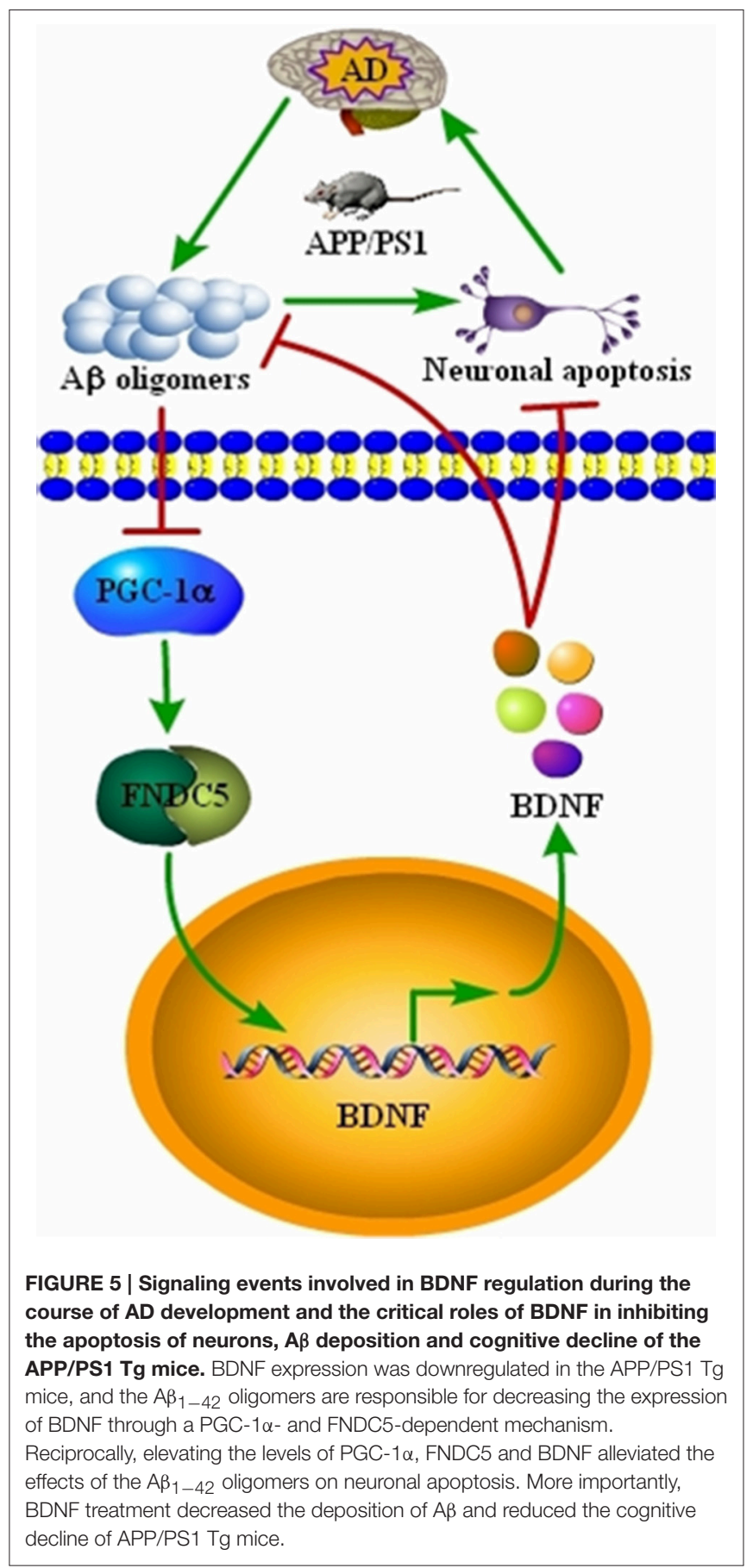

Thus, the aggregation of $A \beta$ may be critical for downregulating the expression of $\mathrm{BDNF}$ during the course of $\mathrm{AD}$ development and progression.

In addition to our finding that the $A \beta_{1-42}$ oligomers exert suppressive effects on the expression of BDNF, we found that PGC- $1 \alpha$ and FNDC5 are involved in regulating the expression of BDNF. In agreement with our observation, PGC- $1 \alpha$ and FNDC5 were demonstrated to be critical for the synthesis of BDNF in the brains of mice (Wrann et al., 2013). Although the current findings are quite limited, PGC- $1 \alpha$ has been suggested to play 
an important role in the brain. For example, a lack of PGC-1 $\alpha$ in the brain is associated with neurodegeneration (Lin et al., 2004; Ma et al., 2010). Outside of the context of AD, PGC-1 $\alpha$ has also been reported to maintain neuronal dendritic spines (Cheng et al., 2012). Apart from PGC-1 $\alpha$, FNDC5 has been reported to trigger the differentiation of PC12 cells into neuronal cells (Ostadsharif et al., 2011). Knockdown of FNDC5 expression in neuronal precursors impairs their development into mature neurons, which suggests a beneficial role for FNDC5 in neurons (Hashemi et al., 2013). Therefore, we added to the previous body research and determined that the $\mathrm{A} \beta_{1-42}$ oligomers suppress the expression of BDNF through a PGC-1 $\alpha$ - and FNDC5-dependent mechanism.

The $A \beta_{1-42}$ oligomers are neurotoxic, so it is easier to demonstrate the neuroprotective effects of BDNF on neurons via disrupting the aggregation of APs. Indeed, BDNF exerted protective effects on neurons and blocked $A \beta_{1-42}$-induced apoptosis. Consistent with our observations, $A \beta$ exhibited dosedependent toxicity in cortical neurons (Geci et al., 2007). In addition, BDNF has been reported to protect neurons from cellular damage (Lindvall et al., 1994). In animal models, BDNF was suggested to protect neurons from tau-induced impairment (Jiao et al., 2016). Furthermore, BDNF was reported to rescue neurogenesis in $\mathrm{A} \beta$-injured neurons (Kitiyanant et al., 2012; Wang et al., 2015). These observations support our data showing that BDNF prevents neuronal death via inhibiting apoptosis in the $A \beta_{1-42}$ oligomers-treated neurons.

Based on this finding, mutating BDNF or blocking its receptor, TrkB, were shown to clearly impair learning ability in the brains of animal models (Egan et al., 2003; Vaynman et al., 2006). The

\section{REFERENCES}

Bloom, G. S. (2014). Amyloid- $\beta$ and tau: the trigger and bullet in Alzheimer disease pathogenesis. JAMA Neurol. 71, 505-508. doi: 10.1001/jamaneurol.2013.5847

Bostrom, P., Wu, J., Jedrychowski, M. P., Korde, A., Ye, L., Lo, J. C., et al. (2012). A PGC1- $\alpha$-dependent myokine that drives brown-fat-like development of white fat and thermogenesis. Nature 481, 463-468. doi: 10.1038/nature10777

Cheng, A., Wan, R., Yang, J. L., Kamimura, N., Son, T. G., Ouyang, X., et al. (2012). Involvement of PGC- $1 \alpha$ in the formation and maintenance of neuronal dendritic spines. Nat. Commun. 3, 1250. doi: 10.1038/ncomms2238

Corona, C., Masciopinto, F., Silvestri, E., Viscovo, A. D., Lattanzio, R., Sorda, R. L., et al. (2012). Dietary zinc supplementation of 3xTg-AD mice increases BDNF levels and prevents cognitive deficits as well as mitochondrial dysfunction. Cell Death Dis. 1, e91. doi: 10.1038/cddis.2010.73

Dun, S. L., Lyu, R. M., Chen, Y. H., Chang, J. K., Luo, J. J., and Dun, N. J. (2013). Irisin-immunoreactivity in neural and non-neural cells of the rodent. Neuroscience 240, 155-162. doi: 10.1016/j.neuroscience.2013.02.050

Egan, M. F., Kojima, M., Callicott, J. H., Goldberg, T. E., Kolachana, B. S., Bertolino, A., et al. (2003). The BDNF val66met polymorphism affects activitydependent secretion of BDNF and human memory and hippocampal function. Cell 112, 257-269. doi: 10.1016/S0092-8674(03)00035-7

Finck, B. N., and Kelly, D. P. (2006). PGC-1 coactivators: inducible regulators of energy metabolism in health and disease. J. Clin. Invest. 116, 615-622. doi: 10.1172/JCI27794

Geci, C., How, J., Alturaihi, H., and Kumar, U. (2007). Beta-amyloid increases somatostatin expression in cultured cortical neurons. J. Neurochem. 101, 664-673. doi: 10.1111/j.1471-4159.2006.04415.x

Glenner, G. G., and Wong, C. W. (1984). Alzheimer's disease: initial report of the purification and characterization of a novel cerebrovascular levels of BDNF in serum are also associated with the severity of dementia (Laske et al., 2007). In a model of AD, upregulation of BDNF ameliorates the cognitive decline of rats ( $\mathrm{Li}$ et al., 2016). Consistent with this observation, a series of investigations have demonstrated that the cognitive decline of the APP/PS1 or 3XTg-AD mice was improved once the expression of BDNF was upregulated by different stimuli (Corona et al., 2012; Xiang et al., 2014). In our study, BDNF played pivotal roles in suppressing the deposition of $A \beta$ and reducing cognitive decline of the APP/PS1 Tg mice.

\section{AUTHOR CONTRIBUTIONS}

DX and XH conceived and performed all of the experiments, participated in the design of the study and wrote the manuscript. $\mathrm{CB}, \mathrm{LM}$, and LP carried out select experiments. HQ interpreted the data and wrote the manuscript.

\section{ACKNOWLEDGMENTS}

This work was supported in part or in whole by the Capital Application Research for Clinical Characteristics (Z151100004015005), the Returnees' Innovation Funds of Navy General Hospital of Chinese PLA (GGCX201207).

\section{SUPPLEMENTARY MATERIAL}

The Supplementary Material for this article can be found online at: http://journal.frontiersin.org/article/10.3389/fnagi. 2017.00065/full\#supplementary-material amyloid protein. Biochem. Biophys. Res. Commun. 120, 885-890. doi: 10.1016/S0006-291X(84)80190-4

Gruden, M. A., Davidova, T. B., Malisauskas, M., Sewell, R. D., Voskresenskaya, N. I., Wilhelm, K., et al. (2007). Differential neuroimmune markers to the onset of Alzheimer's disease neurodegeneration and dementia: autoantibodies to $A \beta_{25-35}$ oligomers, S100b and neurotransmitters. J. Neuroimmunol. 186, 181-192. doi: 10.1016/j.jneuroim.2007.03.023

Hashemi, M. S., Ghaedi, K., Salamian, A., Karbalaie, K., Emadi-Baygi, M., Tanhaei, S., et al. (2013). Fndc5 knockdown significantly decreased neural differentiation rate of mouse embryonic stem cells. Neuroscience 231, 296-304. doi: 10.1016/j.neuroscience.2012.11.041

Holsinger, R. M., Schnarr, J., Henry, P., Castelo, V. T., and Fahnestock, M. (2000). Quantitation of BDNF mRNA in human parietal cortex by competitive reverse transcription-polymerase chain reaction: decreased levels in Alzheimer's disease. Brain Res. Mol. Brain Res. 76, 347-354. doi: 10.1016/S0169-328X(00)00023-1

Jiao, S. S., Shen, L. L., Zhu, C., Bu, X. L., Liu, Y. H., Liu, C. H., et al. (2016). Brainderived neurotrophic factor protects against tau-related neurodegeneration of Alzheimer's disease. Transl. Psychiatry 6, e907. doi: 10.1038/tp.2016.186

Kitiyanant, N., Kitiyanant, Y., Svendsen, C. N., and Thangnipon, W. (2012). BDNF-, IGF-1- and GDNF-secreting human neural progenitor cells rescue amyloid $\beta$-induced toxicity in cultured rat septal neurons. Neurochem. Res. 37, 143-152. doi: 10.1007/s11064-011-0592-1

Kubo, T., Nishimura, S., Kumagae, Y., and Kaneko, I. (2002). In vivo conversion of racemized beta-amyloid ([D-Ser $\left.\left.{ }^{26}\right] \mathrm{A} \beta \mathrm{1}-40\right)$ to truncated and toxic fragments ([D-Ser $\left.{ }^{26}\right] \mathrm{A} \beta$ 25-35/40) and fragment presence in the brains of Alzheimer's patients. J. Neurosci. Res. 70, 474-483. doi: 10.1002/jnr.10391

Laske, C., Stransky, E., Leyhe, T., Eschweiler, G. W., Maetzler, W., Wittorf, A., et al. (2007). BDNF serum and CSF concentrations in Alzheimer's disease, normal 
pressure hydrocephalus and healthy controls. J. Psychiatr. Res. 41, 387-394. doi: 10.1016/j.jpsychires.2006.01.014

Lattanzio, F., Carboni, L., Carretta, D., Candeletti, S., and Romualdi, P. (2016). Treatment with the neurotoxic $A \beta_{25-35}$ peptide modulates the expression of neuroprotective factors Pin 1, Sirtuin 1, and brain-derived neurotrophic factor in SH-SY5Y human neuroblastoma cells. Exp. Toxicol. Pathol. 68, 271-276. doi: 10.1016/j.etp.2016.02.001

Li, Y., Xu, J., Xu, P., Song, S., Liu, P., Chi, T., et al. (2016). Xanthoceras sorbifolia extracts ameliorate dendritic spine deficiency and cognitive decline via upregulation of BDNF expression in a rat model of Alzheimer's disease. Neurosci. Lett. 629, 208-214. doi: 10.1016/j.neulet.2016.07.011

Lin, J., Wu, P.-H., Tarr, P. T., Lindenberg, K. S., St-Pierre, J., Zhang, C., et al. (2004). Defects in adaptive energy metabolism with CNS-linked hyperactivity in PGC-1 $\alpha$ null mice. Cell 119, 121-135. doi: 10.1016/j.cell.2004.09.013

Lindvall, O., Kokaia, Z., Bengzon, J., Elmer, E., and Kokaia, M. (1994). Neurotrophins and brain insults. Trends Neurosci. 17, 490-496. doi: 10.1016/ 0166-2236(94)90139-2

Ma, D., Li, S., Lucas, E. K., Cowell, R. M., and Lin, J. D. (2010). Neuronal inactivation of peroxisome proliferator-activated receptor gamma coactivator $1 \alpha($ PGC-1 $\alpha)$ protects mice from diet-induced obesity and leads to degenerative lesions. J. Biol. Chem. 285, 39087-39095. doi: 10.1074/jbc.M110.151688

Michalski, B., and Fahnestock, M. (2003). Pro-brain-derived neurotrophic factor is decreased in parietal cortex in Alzheimer's disease. Brain Res. Mol. Brain Res. 111, 148-154. doi: 10.1016/S0169-328X(03)00003-2

Murer, M. G., Boissiere, F., Yan, Q., Hunot, S., Villares, J., Faucheux, B., et al. (1999). An immunohistochemical study of the distribution of brain-derived neurotrophic factor in the adult human brain, with particular reference to Alzheimer's disease. Neuroscience 88, 1015-1032. doi: 10.1016/S0306-4522(98)00219-X

Ostadsharif, M., Ghaedi, K., Hossein Nasr-Esfahani, M., Mojbafan, M., Tanhaie, S., Karbalaie, K., et al. (2011). The expression of peroxisomal protein transcripts increased by retinoic acid during neural differentiation. Differentiation 81, 127-132. doi: 10.1016/j.diff.2010.11.003

Pan, X. D., Zhu, Y. G., Lin, N., Zhang, J., Ye, Q. Y., Huang, H. P., et al. (2011). Microglial phagocytosis induced by fibrillar $\beta$-amyloid is attenuated by oligomeric $\beta$-amyloid: implications for Alzheimer's disease. Mol. Neurodegener. 6:45. doi: 10.1186/1750-1326-6-45

Park, H., and Poo, M. M. (2013). Neurotrophin regulation of neural circuit development and function. Nat. Rev. Neurosci. 14, 7-23. doi: 10.1038/ nrn3379

Peng, S., Wuu, J., Mufson, E. J., and Fahnestock, M. (2005). Precursor form of brain-derived neurotrophic factor and mature brain-derived neurotrophic factor are decreased in the pre-clinical stages of Alzheimer's disease. J. Neurochem. 93, 1412-1421. doi: 10.1111/j.1471-4159.2005. 03135.x
Phillips, H. S., Hains, J. M., Armanini, M., Laramee, G. R., Johnson, S. A., and Winslow, J. W. (1991). BDNF mRNA is decreased in the hippocampus of individuals with Alzheimer's disease. Neuron 7, 695-702. doi: 10.1016/0896-6273(91)90273-3

Roberts, H. R., Smartt, H. J., Greenhough, A., Moore, A. E., Williams, A. C., and Paraskeva, C. (2011). Colon tumour cells increase PGE(2) by regulating COX2 and 15-PGDH to promote survival during the microenvironmental stress of glucose deprivation. Carcinogenesis 32, 1741-1747. doi: 10.1093/carcin/bgr210

Sen, A., Nelson, T. J., and Alkon, D. L. (2015). ApoE4 and A $\beta$ oligomers reduce BDNF expression via HDAC nuclear translocation. J. Neurosci. 35, 7538-7551. doi: 10.1523/JNEUROSCI.0260-15.2015

Son, K. K., Patel, D. H., Tkach, D., and Park, A. (2000). Cationic liposome and plasmid DNA complexes formed in serum-free medium under optimum transfection condition are negatively charged. Biochim. Biophys. Acta 1466, 11-15. doi: 10.1016/S0005-2736(00)00176-0

St-Pierre, J., Drori, S., Uldry, M., Silvaggi, J. M., Rhee, J., Jager, S., et al. (2006). Suppression of reactive oxygen species and neurodegeneration by the PGC-1 transcriptional coactivators. Cell 127, 397-408. doi: 10.1016/j.cell.2006.09.024

Vaynman, S. S., Ying, Z., Yin, D., and Gomez-Pinilla, F. (2006). Exercise differentially regulates synaptic proteins associated to the function of BDNF. Brain Res. 1070, 124-130. doi: 10.1016/j.brainres.2005.11.062

Wang, C., Chen, T., Li, G., Zhou, L., Sha, S., and Chen, L. (2015). Simvastatin prevents $\beta$-amyloid(25-35)-impaired neurogenesis in hippocampal dentate gyrus through $\alpha 7 \mathrm{nAChR}$-dependent cascading PI3K-Akt and increasing BDNF via reduction of farnesyl pyrophosphate. Neuropharmacology 97, 122-132. doi: 10.1016/j.neuropharm.2015.05.020

Wrann, C. D., White, J. P., Salogiannnis, J., Laznik-Bogoslavski, D., Wu, J., Ma, D., et al. (2013). Exercise induces hippocampal BDNF through a PGC-1 $\alpha /$ FNDC5 pathway. Cell Metab. 18, 649-659. doi: 10.1016/j.cmet.2013.09.008

Xiang, J., Pan, J., Chen, F., Zheng, L., Chen, Y., Zhang, S., et al. (2014). L-3-n-butylphthalide improves cognitive impairment of APP/PS1 mice by BDNF/TrkB/PI3K/AKT pathway. Int. J. Clin. Exp. Med. 7, 1706-1713.

Yankner, B. A. (1996). Mechanisms of neuronal degeneration in Alzheimer's disease. Neuron 16, 921-932. doi: 10.1016/S0896-6273(00)80115-4

Conflict of Interest Statement: The authors declare that the research was conducted in the absence of any commercial or financial relationships that could be construed as a potential conflict of interest.

Copyright (C) 2017 Xia, Huang, Bi, Mao, Peng and Qian. This is an open-access article distributed under the terms of the Creative Commons Attribution License (CC BY). The use, distribution or reproduction in other forums is permitted, provided the original author(s) or licensor are credited and that the original publication in this journal is cited, in accordance with accepted academic practice. No use, distribution or reproduction is permitted which does not comply with these terms. 